\title{
Research on Energy Saving Audit of Construction Based on Carbon Emission Perspective
}

\author{
Huan $\mathrm{Liu}^{1, *}$, Yu Zhou ${ }^{1}$ \\ ${ }^{1}$ Audit Research Institute of the National Audit Office, Government Management College of Peking University, Army Logistics \\ College, China
}

\begin{abstract}
This paper studies the contents and methods of building energy conservation audit from the perspective of carbon emission, the purpose of which is to have a fair idea of the existing buildings' carbon emissions, get the hang of the similar buildings' carbon emission laws, transform existing buildings, supervise and guide the proposed building, and finally achieve the ultimate aims of energy-efficiency, carbon reduction and environmental protection in construction. In this paper, how to examine, analyse and evaluate the energy conservation of buildings is studied and explored, and a beneficial attempt is made on the specific audit method of carbon emissions.
\end{abstract}

\section{Related concepts}

\subsection{Carbon footprint, carbon emissions and carbon dioxide equivalent}

\subsubsection{Ccarbon footprint}

The carbon footprint refers to the "carbon consumption" directly or indirectly caused by the activities and products of individuals and organizations. Emissions and diffusion of greenhouse gases such as carbon dioxide $\left(\mathrm{CO}_{2}\right)$, methane $\left(\mathrm{CH}_{4}\right)$, nitrous oxide $\left(\mathrm{N}_{2} \mathrm{O}\right)$, sulphur hexafluoride $\left(\mathrm{SF}_{6}\right)$ as well as other atmospheric pollutants have a significant impact on the global climate, which lead to environmental degradation and warming. Using the carbon footprint as a measure of greenhouse gas emissions is to track the damage to the environment. The more carbon consumed, the more greenhouse gases emitted. In some Western countries and developed regions, the carbon footprint has become a new indicator of the environmental impact of greenhouse gas emissions resulting from energy consumption.

\subsubsection{Carbon emissions and global warming potential}

Carbon emission is the general name of greenhouse gas emissions. As carbon dioxide is the most important gas in the greenhouse gas, we often use carbon to represent greenhouse gases. The global warming potential (GWP) is a parameter that is designed to evaluate the relative effects of various greenhouse gases to climate change, by converting the effect of each specific type of greenhouse gas to carbon dioxide. For example, the GWP of $\mathrm{CH}_{4}$ is 21 , and the GWP of $\mathrm{N}_{2} \mathrm{O}$ is 310 ., so the reduction of 1 tons $\mathrm{CH}_{4}$ emissions are equivalent to 21 tons $\mathrm{CO}_{2}$ emission, and the reduction of 1 tons $\mathrm{N} 2 \mathrm{O}$ emissions are equivalent to 310 tons $\mathrm{CO}_{2}$ emission.

\subsubsection{Carbon dioxide equivalent}

The contribution of various greenhouse gases emitted by human activities to the greenhouse is different, and as $\mathrm{CO}_{2}$ is the main gas produced by human activities to greenhouse effect, so we specify carbon dioxide equivalence as the basic unit of measurement of greenhouse effect in order to measure the results of the overall greenhouse effect. The specific measurement is: the carbon dioxide equivalent of a greenhouse gas $=$ the mass of the gas $\times$ the GWP of the gas. Thus, it can be seen that the measurement method such as carbon dioxide equivalent can be used to construct a reasonable framework scientifically and intuitively in order to measure the relative benefits of various greenhouse gases and emission reductions.

\subsection{Building energy saving audit based on carbon emission}

Building energy saving audit is an activity that auditors describing and measuring the greenhouse gas emissions generated by building energy consumption, analyzing the relative economic benefits of reducing greenhouse gases, assessing the energy consumption levels and usage effectiveness over the life cycle of buildings from the perspective of carbon footprint. The purpose of the audit is to assess the energy consumption and carbon emissions of buildings, supervise and guide the planning and design of the buildings to be built and the energysaving transformation of existing buildings, and

\footnotetext{
Huan Liu: liuhuan10@sina.com
} 
ultimately guide the scientific use of energy and reduce carbon emissions in all kinds of buildings.

\section{Key points of building energy saving audit based on carbon emission perspective}

\subsection{Planning and design audit of proposed building}

\subsubsection{Overall planning and design audit of proposed building}

Firstly, we should examine whether the construction planning is reasonable and can meet the demands. For example, whether it follows the principle of centralized deployment, integrated construction and intensive support, and if there is bad phenomena of excess areas or plans; Secondly, we should review the layout of the building design. For example, whether the orientation and density of the single barracks is reasonable, and if the heat of the single building loss is less than it gains, and the heat island phenomenon will occur in the highdensity area in summer. Thirdly, we should examine the building shape coefficient. For example, if the building has a reasonable shape and the plane form of the building is reasonable, if the outer surface reduces unnecessary concave and convex changes, and if the shape coefficient of the wart readiness building is controlled within a reasonable range as far as possible.

\subsubsection{Main structure design audit of proposed building}

Firstly, we should examine whether the energy saving technology is used to improve the thermal performance of the building enclosure structure, change the thermal environment and reduce the carbon emission of the building by means of heat preservation, heat insulation, sun shade, ventilation, etc. Secondly, we should examine whether the enclosure design improve the heat and cold load of the building such as the heat loss caused by heat transfer on the external wall and roof, the proportion of energy consumption and the thermal conductivity whether meets the requirements of energy conservation, whether the wall adopts the forms of heat preservation such as external insulation, internal insulation or sandwich insulation, whether the window / wall ratio is controlled reasonably on the premise of ensuring sunshine, daylighting, ventilation and view requirements.

\subsubsection{Natural energy using audit of proposed building}

First of all, we should examine whether reasonable ventilation is designed to replenish fresh air to people living in residential buildings and to improve the indoor thermal and wet environment, to reduce the indoor temperature in summer, to avoid the cold winds infiltration in winter, to increase the heat loss on the outer surface of the building, and whether the ventilation is considered in summer and winter. Secondly, we should examine whether reasonable lighting is designed to makes full use of natural light sources, save energy consumption for lighting, and ensure good indoor natural light. Thirdly, we should examine whether solar energy, wind energy and geothermal energy is designed to be used reasonably, such as vacuum tube solar collector (water heater), solar panels, solar water supply, ground source heat pump and so on.

\subsubsection{Design audit of heating and refrigeration equipment system}

First of all, we should examine whether the equipment system design has been absorbed in the architectural design as early as possible, so that the building and the equipment type design can cooperate with each other, whether there is a contradiction between the equipment system design and the building structure so as to affect the operation efficiency of heating and refrigeration equipment. For example, the location of the machine room is poor, the area is too small, the pipes and electrical devices are crowded. Secondly, we should examine whether the design of the cooling and heating load of the room is reasonable. For example, the design whether takes into account the cold load (heat load) resulting from the indoor and outdoor temperature difference, the solar radiation, indoor lighting and other indoor equipment. Thirdly, we should examine the design standard of indoor temperature and humidity of heating refrigeration system. Such as whether to combine the comfort of human body with the special functional requirements of architecture, whether the indoor temperature and humidity standard is reasonable, and whether there is blind pursuit of high standards.

\subsection{Construction audit of proposed building}

\subsubsection{Construction organization management and construction supervision audit}

First of all, we should examine whether the constructor has a complete plan of energy saving work plan, whether or not to establish a responsibility system for energy saving and to decompose the responsibility to all the specific personnel participating in the activities. Secondly, we should examine whether the supervisor can grasp the progress plan at any time, understand the situation of energy saving and consumption reduction in each stage, urge the construction organization to strictly follow the energy saving plan, and put forward the correct opinion to the pertinence and maneuverability of technologies and measures in construction energy saving scheme.

\subsubsection{Construction technology and material selection audit}


First of all, we should examine whether the constructor strictly implement the relevant regulations of prohibiting or restricting backward technology, process and products, whether to give priority to the adoption of equipments with mature technology and low energy consumption, whether to actively adopt new technologies, new materials, new processes and new products to reduce energy consumption in heating, refrigeration and lighting. Secondly, we should examine whether the constructor use water-saving products and equipment and pay attention to the recycling of water resources, whether to use intelligent load limiter and energy-saving construction lamps. Thirdly, we should examine whether to use high performance concrete, steel, bamboo, plastic formwork instead of wood, whether there is accurate material procurement and management plan to prevent overuse and wastage in the course of material use and storage, whether to use new technology with obvious material saving effect, such as high efficiency steel bar and prestressing force technology, steel bar straight thread connection, electros lag pressure welding technology and so on.

\subsection{Use and maintenance audit of existing buildings}

\subsubsection{Management audit of existing buildings}

We should examine whether the relevant restraint and incentive system is in place, which can strictly control personnel waste and the operation of heavy energy consumption equipment, whether the functional area is reasonable, such as setting up the personnel intensive organization or the department of frequent access in the convenient place of transportation and reducing the elevator operation, whether the partition management setting of the refrigeration heating system is reasonable, such as the air supply and refrigeration heating of different regional space should be individually designed.

\subsubsection{Using audit of existing buildings}

We should check the energy saving in the process of using the refrigeration heating system and examine whether the operation period is selected according to the actual needs and makes each cold and heat source equipment operate under reasonable and efficient load rate, whether to control the operation of the fresh air unit and exhaust air unit reasonably and to avoid the unreasonable air flow between the non-air conditioning space and the air conditioning space such as the stairwell and the elevator, whether to use sunshade measures to avoid direct sunlight and reduce open doors and windows in order to reduce heat exchange, and whether to use energy-saving office appliances.

\subsection{Demolition and recycling audit of existing buildings}

\subsubsection{Scrapping and functional conversion audit of existing buildings}

We should examine whether the determination of endof-life buildings is reasonable, whether they have not reached the expected service life or can be reused. We also should review the identification process and transformation conditions of functional transformation building and make sure it can meets the functional needs.

\subsubsection{Demolition and material recycling audit of existing buildings}

We should examine whether the construction waste is reasonably classified and sorted, whether the wastes that can be directly used are converted into economic value, and whether wastes that cannot be directly used are reused as renewable resources.

\section{Measuring method of building energy saving audit based on carbon emission perspective}

Carbon emissions from buildings can be quantified through fuel consumption and its greenhouse gas emission factors. The method of calculation is:

\section{$\mathrm{CO}_{2}$ Emissions $=$ \\ $\sum$ Fuel Consumption $\times$ Emission Factors}

\section{$\mathrm{CH}_{2} / \mathrm{N}_{2} \mathrm{O}$ Emissions $=$ $\sum$ Fuel Consumption $\times$ Emission Factors $\times G W P$}

The calculation of greenhouse gas emissions involves fuel type, fuel consumption and emission factors, the calculations is greenhouse gas emission mass and expressed in terms of carbon dioxide equivalent. The relative global warming potential of methane and nitrous oxide is shown in Table 1. Different greenhouse gases have different emission factor values for different types of fuels, as shown in Table 2.

Table 1. The relative global warming potential of greenhouse gas

\begin{tabular}{|c|c|c|}
\hline $\mathbf{C O}_{2}$ & $\mathrm{CH}_{4}$ & $\mathbf{N}_{2} \mathbf{O}$ \\
\hline 1 & 21 & 310 \\
\hline
\end{tabular}


Table 2. The emission factors of $\mathrm{CO}_{2}, \mathrm{CH}_{4}$ and $\mathrm{N}_{2} \mathrm{O}$

\begin{tabular}{|c|c|c|c|c|}
\hline \multirow{2}{*}{$\begin{array}{l}\text { Fuel or } \\
\text { Energy }\end{array}$} & \multirow{2}{*}{ Unit } & \multicolumn{3}{|c|}{ Greenhouse Gas Emissions Factor } \\
\hline & & $\mathrm{CO}_{2}$ & $\mathrm{CH}_{4}$ & $\mathbf{N}_{2} \mathbf{O}$ \\
\hline Diesel Oil & 1 & $2.614 \mathrm{~kg}$ & $0.0239 \mathrm{~g}$ & $0.0074 \mathrm{~g}$ \\
\hline LPG & $\mathrm{kg}$ & $3.017 \mathrm{~kg}$ & $0.0020 \mathrm{~g}$ & $0.0000 \mathrm{~g}$ \\
\hline Kerosene & 1 & $2.429 \mathrm{~kg}$ & $0.0241 \mathrm{~g}$ & $0.0076 \mathrm{~g}$ \\
\hline Charcoal & $\mathrm{kg}$ & $2.970 \mathrm{~kg}$ & $5.5290 \mathrm{~g}$ & $0.0276 \mathrm{~g}$ \\
\hline Towngas & $\mathrm{m}^{3}$ & $2.815 \mathrm{~kg}$ & $0.0446 \mathrm{~g}$ & $0.0099 \mathrm{~g}$ \\
\hline $\begin{array}{l}\text { Electric } \\
\text { Energy }\end{array}$ & kilowatt & $0.7 \mathrm{~kg}$ & - & - \\
\hline
\end{tabular}

\section{Audit results using}

\subsection{To provide guidance for the renovation and management of existing buildings}

For the existing buildings, which do not meet the national building energy conservation standards and emission regulations, the auditors should identify the reasons. The auditors also can correct unreasonable energy conservation systems, unsound management measures and lack of energy saving consciousness personnel behaviors, provide correct and efficient guidance for energy use and carbon emission reductions, avoid waste and additional carbon emissions due to construction management and use. For the structures and systems of high-energy-efficient and high-emission enclosures, heating systems, heating and refrigeration systems, lighting systems and hot water supply, the constructor should carry out facilities reconstruction, structural reinforcement or equipment renewal, such as improving the thermal insulation performance of the structure, optimizing power distribution and power transmission, repair leakage pipe network, avoid equipment out of service and so on.

\subsection{To provide planning, design and construction guidance for proposed buildings}

During the process of planning, design and construction of proposed building, we can get some experiences from the audit results of similar type of building, so as to improve the energy-saving structure, allocate limited resources and energy, improve the decision-making, organization and management of the project itself, and promote the use of new materials, new equipment and new technology.

\subsection{To provide basis for the formulation of low- carbon building standards}

The building energy conservation audit is the truest and most comprehensive summary of the energy saving and carbon emission of buildings, which can refine the building energy saving experiences and lessons, reflect the law of building energy conservation. The audit result is the establishment of formulating energy saving and emission reduction targets, low-carbon building standards and environmental protection and energysaving policies.

\section{Conclusions}

Building energy saving audit is one of the important means to reduce the carbon emission of building. We should distinguish between the building under construction and to be built, and supervise and evaluate the whole life of its planning, design, construction, maintenance and use, scrapping and demolition respectively, so as to maximize the efficiency of energy use and reduce environmental pollution and damage.

\section{References}

1. Pankaj Bhatia, Janet Ranganathan and World Business Council for Sustainable Development (WBCSD), The Greenhouse Gas Protocol:A Corporate Accounting and Reporting Standard (Revised Edition), (2004)

2. International Standard on Greenhouse Gases-Part1, Specification with guidance at the organization level for quantification and reporting of greenhouse gas emissions and removals, ISO 14064-1

3. Environmental Protection Agency, Mechanical and Electrical Engineering Department. Guidelines for the accounting and reporting of greenhouse gas emissions and abatement of buildings (commercial, domestic or public) in Hong Kong, (2008)

4. Enmao Wang, Research on Investment decision of Energy-saving Housing based on Life-cycle cost, Doctoral thesis of Xian Architectural Science and Technology University, (2008) 